\title{
Carotenoid Profiles of Potato Breeding Lines and Selected Cultivars
}

\author{
Sergey Nesterenko and Kenneth C. Sink ${ }^{1}$ \\ Department of Horticulture, Michigan State University, East Lansing, MI 48824
}

Additional index words. high performance liquid chromatography, lutein, Solanum tuberosum, xanthophylls, zeaxanthin

\begin{abstract}
Lutein and zeaxanthin are becoming established as carotenoids beneficial for protection against common age-associated eye diseases. Thus, 15 potato (Solanum tuberosum subsp. tuberosum L.) breeding lines, cultivars Atlantic, Spunta, and Yukon Gold; and orange flesh OR-4 were surveyed for carotenoid profiles. Seven carotenoids, including violaxanthin, neoaxanthin, antheraxanthin, lutein, zeaxanthin, $\beta$-cryptoaxanthin, and $\beta$-carotene, were identified in the 19 genotypes. Violaxanthin and lutein were the prominent carotenoids detected in all genotypes studied. Neoaxanthin and antheraxanthin were found in $26 \%$ and $63 \%$ of the genotypes, respectively. $\beta$-Cryptoaxanthin, zeaxanthin, and $\beta$-carotene were found in only $5 \%, 10 \%$, and $16 \%$ of the genotypes, respectively. Lutein varied from 19.8 to $119.0 \mu \mathrm{g} \cdot 100 \mathrm{~g}^{-1}$ fresh weight across the 15 white- or yellow-flesh breeding lines. In contrast, zeaxanthin was detected at a low level in only one breeding line and at high level in OR-4. The three cultivars had profiles typical of yellow-flesh potatoes 'Spunta' and 'Yukon Gold'; while 'Atlantic' had a typical white-flesh profile and a trace of zeaxanthin. The carotenoid baseline data established in this study provide information for activities to enhance potato for lutein and zeaxanthin.
\end{abstract}

In regard to human health and carotenoids in the diet, more recent attention has focused on lutein and zeaxanthin and their role in protecting against age-related macular degeneration (AMD) (Curran-Celentano et al., 2001; Mares-Perlman et al., 2002). While epidemiologic evidence indicates a role for these two carotenoids in eye disease, according to MaresPerlman et al. (2002) the overall evidence is still lacking to support increased consumption of lutein and zeaxanthin for a health benefit. These two carotenoids join the established and continuing emphasis placed on pro-vitamin A, principally $\beta$-carotene, playing a key role in vision health. Also, lycopene is recommended for human diets, principally through consumption of tomato-based products for reduction of prostate cancer, although it is not established if lycopene or micronutrients provide the benefit (Giovannucci, 1999). Continued expansion of our understanding of the importance of carotenoids in human health supports the promotion of increased consumption of fresh fruits and vegetables, based on reduction of cardiovascular diseases, some cancers, and macular degeneration (Mayne, 1996).

Potato is the most important non-cereal food crop in the world, but efforts to change the nutrient composition of potato through breeding or genetic engineering lag behind those focused on agronomic practices. Yellow-fleshed potatoes are generally characterized by higher contents of lutein, violaxanthin, and total caroteniods. Such potato cultivars were first accepted by European consumers. In the United States, there are now many potato cultivars, in ad-

Received for publication 15 July 2002. Accepted for publication 4 Dec. 2002.

${ }^{1}$ To whom reprint requests should be addressed. Phone: 517-355-4598; fax 517-353-0890; e-mail address: sink@msu.edu dition to those mentioned by Haynes (2000), with varying intensities of yellow flesh. Haynes (2000) mentioned that interest in yellow-flesh potatoes in the United States arises from their perceived better taste, improved cooking quality, and higher nutritional value. Yellow-flesh pigmentation in potato is controlled by a single gene that is dominant to white flesh (Fruwirth, 1912), and was subsequently designated $Y$ mapped to chromosome 3 (Bonierbale et al., 1988). Brown et al. (1993) found the mutant $O r$ in a hybrid population of $S$. phureja-S. stenotomum that is dominant to the alleles $Y$ and $y$, which determine yellow and white flesh, respectively. The main effect of $O r$ is to increase zeaxanthin [2055 $\mu \mathrm{g} \cdot 100 \mathrm{~g}^{-1}$ fresh weight $(\mathrm{FW})]$ such that tubers have an orange phenotype. The range in lutein in the diploid potatoes segregating for flesh color in Brown's study was 98 to $181 \mu \mathrm{g} \cdot 100 \mathrm{~g}^{-1} \mathrm{FW}$.

Several other studies also have examined the carotenoid composition of potato tubers.

Using column chromatography, Brunstetter and Wiseman (1947) found that immature tubers of the cultivar Katahdin had total pigments of $3.0 \mathrm{mg}$ dry weight (DW) and, of that, 0.5 to $0.77 \mathrm{mg}$ was lutein. Pendlington et al. (1965) found eight major and four minor carotenoids in six British potato cultivars. The eight abundant ones were found in all six cultivars, and it was observed that lutein increased during tuber storage. Iwanzik et al.(1983) reported that total xanthophylls of 13 yellow-flesh cultivars varied between 27 to $343 \mu \mathrm{g} \cdot 100 \mathrm{~g}^{-1} \mathrm{FW}$. The main carotenoid found was violaxanthin, 8 to $244 \mu \mathrm{g} \cdot 100 \mathrm{~g}^{-1} \mathrm{FW}$; followed by lutein, 15 to $88 \mu \mathrm{g} \cdot 100 \mathrm{~g}^{-1} \mathrm{FW}$; lutein-5,6-epoxide, 2.7 to $51.0 \mu \mathrm{g} \cdot 100 \mathrm{~g}^{-1} \mathrm{FW}$; and neoaxanthin, 1.2 to $8.7 \mu \mathrm{g} \cdot 100 \mathrm{~g}^{-1} \mathrm{FW}$. Lu et al. (2001) studied 10 yellow-flesh and one white-flesh clones that originated from the same Solanum sp. cross used by Brown et al. (1993). For the 10 yellow-flesh clones, the levels for lutein and zeaxanthin ranged from 56 to 531, and 5 to 44 $\mu \mathrm{g} \cdot 100 \mathrm{~g}^{-1} \mathrm{FW}$, respectively. The levels of lutein in these diploid yellow-flesh potato genotypes are considerably higher than in any previous report. Interestingly, total carotenoids, ranging from 283 to $1435 \mu \mathrm{g} \cdot 100 \mathrm{~g}^{-1} \mathrm{FW}$ for the 10 clones, is higher than the $111 \mu \mathrm{g} \cdot 100 \mathrm{~g}^{-1}$ FW for 'Yukon Gold' (Lu et al., 2001). Across the 10 genotypes, the levels of neoxanthin, violaxanthin, and lutein-5,6-epoxide were generally higher than those reported for the German cultivars by Iwanzik et al. (1983). Since potato is an important world food crop and the carotenoid content may be enhanced through breeding, we carried out an highperformance liquid chromatography (HPLC) analysis of 15 breeding lines, three cultivars, and OR-4 to establish a baseline of the types of carotenoids present, with emphasis on the status of lutein and zeaxanthin.

\section{Materials and Methods}

Fifteen potato lines from the Michigan State Univ. breeding program were kindly provided by $D$. Douches. These are all advanced breeding lines, 12 of which have yellow flesh and three with white flesh, and represent a range of pedigrees. OR-4, (kindly provided by C.R. Brown, USDA/ARS, Prosser, Wash.), and three cultivars, 'Atlantic', 'Spunta', and 'Yukon Gold', were also studied. These 19 genotypes were planted at the Lake City Experiment Station, Lake City, Mich., in May 2001 and harvested in September. After harvest, the tubers were stored at $4{ }^{\circ} \mathrm{C}$ and $95 \%$ relative humidity in paper bags. The extraction procedure used was method II-xanthophylls from Brown et al. (1993) with some minor changes. These changes were: first, the tubers in our study ranged in FW from 40 to $100 \mathrm{~g}$, such that one to three tubers of some of the 19 genotypes were needed to yield the $100 \mathrm{~g}$ FW. Second, an internal standard was not employed. Third, the tuber pieces were homogenized in the same acetone-ascorbic acid mix used by Brown et al. (1993), but twice, for 3 min each, and again until the extract was colorless. Fourth, the extracts were redissolved in at least $10-15 \mathrm{~mL}$ of acetone and passed through a Millipore $0.22-\mu \mathrm{m}$ Millex GV filter. Fifth, the extracts were then dissolved in $5 \mathrm{~mL}$ of $100 \%$ ethanol, filtered $(0.22 \mu \mathrm{m})$, and analyzed directly by HPLC or stored at $-80{ }^{\circ} \mathrm{C}$ for later analysis.

Carotenoid analyses were performed on an automated, HPLC system (Waters, Milford, Mass.) using a Model 717 autosampler, a Model 510 pump, and a Waters 996 Photodiode Array Detector. A C30 column (4.6 × $250 \mathrm{~mm}$; YMC, Inc., Wilmington, N.C.) with $5-\mu \mathrm{m}$ particle size and $120 \mathrm{~A}$ was used, as it effectively distinguishes similar geometrical structures of carotenoids (Taungbodhitham et al., 1998). The guard column $(4 \times 23 \mathrm{~mm})$ used was a YMC S-5. The mobile phase was 89: $11 \mathrm{MeOH} /$ methyl tert-butyl ether (v/v) with a flow rate of $1.0 \mathrm{~mL} \cdot \mathrm{min}^{-1}$ (Lessin et al., 1997). Isocratic elution was used, as we found no difference between it and gradient elution in preliminary studies. Detection for carotenoid 
Breeding, Cultivars, Rootstocks, \& Germplasm Resources

Table 1. Carotenoid composition in 15 MSU potato lines, WSU OR-4, and 3 cultivars

\begin{tabular}{|c|c|c|c|c|c|c|c|c|c|}
\hline \multirow[b]{2}{*}{ Genotype } & \multicolumn{9}{|c|}{ Carotenoid composition $\left(\mu \mathrm{g} \cdot 100 \mathrm{~g}^{-1} \mathrm{FW}\right)$} \\
\hline & Violaxanthin & Neoxanthin & Antheraxanthin & Lutein & Zeaxanthin & $\beta$-cryptoxanthin & $\beta$-carotene & Total & Flesh color \\
\hline \multicolumn{10}{|c|}{ Michigan State Univ. } \\
\hline B106-7 & $4.8 \pm 0.1^{z}$ & $\mathrm{ND}^{\mathrm{y}}$ & ND & $35.2 \pm 1.5$ & ND & ND & ND & $47.8 \pm 1.5$ & White \\
\hline G004-3 & $3.1 \pm 0.4$ & ND & $0.9 \pm 0.2$ & $30.5 \pm 5.3$ & ND & ND & ND & $38.0 \pm 6.8$ & White \\
\hline G274-3 & $27 \pm 3.2$ & $6.6 \pm 1.3$ & $5.3 \pm 1.1$ & $36.6 \pm 2.7$ & ND & ND & ND & $86.9 \pm 5.6$ & White \\
\hline H031-5 & $8.6 \pm 0.9$ & ND & $0.6 \pm 0.1$ & $19.8 \pm 2.1$ & ND & ND & ND & $37.6 \pm 1.2$ & White \\
\hline J132-1Y & $88.6 \pm 6.4$ & ND & ND & $119.0 \pm 10.0$ & ND & ND & $3.7 \pm 0.9$ & $265 \pm 5.0$ & White \\
\hline J168-2Y & $28.8 \pm 6.3$ & ND & $5.4 \pm 1.9$ & $51.1 \pm 3.1$ & ND & ND & ND & $51.1 \pm 4.6$ & White \\
\hline E048-2Y & $124.3 \pm 9.7$ & ND & $11.3 \pm 0.9$ & $81.6 \pm 9.2$ & ND & ND & ND & $260.3 \pm 16.6$ & Yellow \\
\hline E149-1Y & $86.8 \pm 5.0$ & ND & ND & $59.3 \pm 2.6$ & $1.68 \pm 0.2$ & ND & ND & $169.2 \pm 7.4$ & Yellow \\
\hline F165-6RY & $62.4 \pm 7.0$ & ND & ND & $61.8 \pm 5.4$ & ND & ND & ND & $171.9 \pm 11.4$ & Yellow \\
\hline G145-1Y & $50.2 \pm 9.2$ & $8.3 \pm 1.6$ & $10.2 \pm 1.5$ & $48.1 \pm 3.9$ & ND & ND & ND & $125.3 \pm 15.3$ & Yellow \\
\hline MSD040-4RY & $70.3 \pm 5.0$ & ND & $9.3 \pm 1.7$ & $54.2 \pm 3.4$ & ND & ND & ND & $168.9 \pm 11.2$ & Yellow \\
\hline J033-6Y & $41.8 \pm 4.3$ & $19.9 \pm 3.7$ & $7.1 \pm 2.9$ & $34.8 \pm 3.6$ & ND & ND & ND & $107.5 \pm 6.5$ & Yellow \\
\hline J033-10Y & $58.8 \pm 4.2$ & $20.2 \pm 0.6$ & $9.6 \pm 0.9$ & $47.5 \pm 4.7$ & ND & ND & ND & $142.2 \pm 8.3$ & Yellow \\
\hline J049-1Y & $53.5 \pm 6.4$ & $7.1 \pm 2.3$ & $6.4 \pm 1.2$ & $50.4 \pm 4.6$ & ND & ND & ND & $123.3 \pm 9.1$ & Yellowish \\
\hline I201-2PY & $90.7 \pm 7.0$ & ND & $\mathrm{ND}$ & $43.3 \pm 2.7$ & ND & ND & ND & $160.6 \pm 11.0$ & Yellow-purple \\
\hline \multicolumn{10}{|c|}{ USDA/ARS, Prosser } \\
\hline OR-4 & $99.3 \pm 9.4$ & ND & $227.6 \pm 27.9$ & $82.8 \pm 7.3$ & $476.3 \pm 24.5$ & $11.3 \pm 0.6$ & $2.9 \pm 0.7$ & $878.2 \pm 58.9$ & Orange \\
\hline \multicolumn{10}{|l|}{ Cultivar } \\
\hline Atlantic & $4.1 \pm 0.5$ & ND & $3.9 \pm 0.4$ & $21.3 \pm 1.6$ & ND & ND & ND & $38.1 \pm 3.3$ & White \\
\hline Spunta & $89.9 \pm 9.5$ & ND & ND & $86.6 \pm 7.1$ & ND & ND & ND & $206.9 \pm 9.1$ & Yellow \\
\hline Yukon Gold & $46.3 \pm 4.1$ & ND & ND & $45.3 \pm 1.9$ & $3.2 \pm 0.3$ & ND & ND & $113.6 \pm 6.2$ & Yellow \\
\hline
\end{tabular}

${ }^{2}$ Standard deviation.

${ }^{y}$ Not detected.

peaks was in the range 350 to $550 \mathrm{~nm}$.

Carotenoid standards: $\beta$-carotene (Sigma), $\beta$-cryptoxanthin, zeaxanthin, and lutein (Roche, France); and antheraxanthin, neoxanthin, zeaxanthin, violaxanthin, and $\alpha$-carotene (DHI, Denmark) were used to establish the calibration curves. The identification of carotenoids was confirmed by their spectral characteristics, absorption maximum, retention time, fine structure, and by spiking of sample peaks with carotenoid standards (Britton et al., 1999). Waters Millenium software was used to match all characteristics. For quantitative determination, appropriate standards (zeaxanthin, $0.705 \mathrm{mg} \cdot \mathrm{L}^{-1}$; lutein, $0.082 \mathrm{mg} \cdot \mathrm{L}^{-1}$ ) were run prior to each set of samples. Quantitative data were calculated from peak areas by using the Lambert-Beer law.

Fresh tubers of each genotype were extracted 5 to 6 times. Each sample was injected on the HPLC system a minimum of 3 times. Data are reported as the mean of each line \pm SE (Table 1.).

\section{Results and Discussion}

Seven carotenoids, as verified by contrasts to standards, were detected in the extracts of the 15 breeding lines, three cultivars, and OR4 (Table 1and Fig.1). Lutein-5,6-epoxide was not included in our study. Violaxanthin and lutein were the prominent carotenoids as both were found in all genotypes studied. In the six white-flesh lines, violaxanthin ranged from 3.1 to $28.8 \mu \mathrm{g} \cdot 100 \mathrm{~g}^{-1} \mathrm{FW}$, with a mean of 12.7 $\mu \mathrm{g} \cdot 100 \mathrm{~g}^{-1} \mathrm{FW}$, while in the eight yellow-flesh lines, the range was higher, from 41.8 to 124.3 $\mu \mathrm{g} \cdot 100 \mathrm{~g}^{-1} \mathrm{FW}$, and the mean was $68.5 \mu \mathrm{g} \cdot 100$ $\mathrm{g}^{-1} \mathrm{FW}$. Violaxanthin was likewise the prominent carotenoid found by Iwanzik et al. (1983) in 13 yellow-flesh cultivars. In contrast, the diploid yellow-flesh clones studied by Lu et al. (2001) averaged just slightly higher in lutein- 5,6-epoxide, $231.1 \mu \mathrm{g} \cdot 100 \mathrm{~g}^{-1} \mathrm{FW}$, compared to violaxanthin at $227.9 \mu \mathrm{g} \cdot 100 \mathrm{~g}^{-1} \mathrm{FW}$.

Lutein ranged from 19.8 to $119.0 \mu \mathrm{g} \cdot 100$ $\mathrm{g}^{-1} \mathrm{FW}$ across the 19 genotypes, and averaged 44.8 and $57.0 \mu \mathrm{g} \cdot 100 \mathrm{~g}^{-1} \mathrm{FW}$ for the whiteand yellow-flesh cultivars, respectively. The range for lutein was 34 to $86 \mu \mathrm{g} \cdot 100 \mathrm{~g}^{-1} \mathrm{FW}$; which is similar to that reported by Iwanzik et al. (1983), but they had one cultivar with a lower reading of $15 \mu \mathrm{g} \cdot 100 \mathrm{~g}^{-1} \mathrm{FW}$. Brown et al. (1993) recorded both a broader range and one clone with lutein at $181 \mu \mathrm{g} \cdot 100 \mathrm{~g}^{-1}$ FW. Lu et al. (2001) reported a still higher average, $179 \mu \mathrm{g} \cdot 100 \mathrm{~g}^{-1} \mathrm{FW}$ lutein, and peak level of $531 \mu \mathrm{g} \cdot 100 \mathrm{~g}^{-1} \mathrm{FW}$. The latter value was $\approx 4.5$ fold higher than we observed, and 3 -fold higher than that of Brown et al. (1993). Neoaxanthin and antheraxanthin were found in $26 \%$ and $63 \%$ of the genotypes, respectively, while $\beta$-cryptoaxanthin, zeaxanthin, and $\beta$ carotene were only found in $5 \%, 10 \%$, and $16 \%$, respectively, of all genotypes examined. In general, the levels of zeaxanthin and lutein we observed in the tetraploid breeding lines were lower than those reported for the diploid clones (Lu et al., 2001). Whether higher xanthophyll values can be achieved through breeding and selection within tetraploids vs. an apparently easier means using diploid clones remains to be resolved.

'Yukon Gold' (YG) was included in the analysis as it is the first yellow-flesh cultivar introduced to North America, and is now widely accepted in the United States. YG thus provides a baseline for comparisons of yellow-flesh clones and cultivars in potato carotenoid studies. The carotenoid profile observed for YG was similar to that found by Lu et al. (2001), but neoxanthin was not detected and lutein was $\approx 2$-fold the level of $23 \mu \mathrm{g} \cdot 100 \mathrm{~g}^{-1} \mathrm{FW}$ found previously (Table 1). Still, total carotenoid levels for YG were 111 herein and $113.6 \mu \mathrm{g} \cdot 100 \mathrm{~g}^{-1} \mathrm{FW}$ by Lu et al.
(2001). Comparisons to the results of Lu et al. (2001) need to consider that a C18 column with an isocratic mobil phase mixture of methylene chloride-methanol was used, and xanthophylls quantified as lutein equivalents. That the results reported herein are similar to those of Lu et al. (2001) suggest that differences in cultivars are most likely related to the samples and not the analytical methods. OR-4 had the highest total carotenoid level (Fig. 1), slightly $>3$-fold more than the next highest genotype, J132-1Y.However, the content of lutein 82.8 and zeaxanthin $476.3 \mu \mathrm{g} \cdot 100 \mathrm{~g}^{-1} \mathrm{FW}$ for OR-4 were much lower than those reported by Brown et al. (1993) for the original orange parent D6.11 and the mean values for orange $\mathrm{X}$ white backcross segregants they studied. Yet, the levels of zeaxanthin and lutein detected herein, principally the latter, are sufficient to yield orange-pigmented tubers; thus confirming the observations of Brown et al. (1993). Interestingly, we found other carotenoids present in OR-4 in addition to lutein and the high levels of zeaxanthin previously reported in orange potato genotypes (Brown et al., 1993). OR-4 also has high contents of violaxanthin, 20-fold more antheraxanthin than the next highest genotype, $\beta$-cryptoaxanthin, and a small quantity of $\beta$-carotene (Table 1 ; Fig. 1). While zeaxanthin is the principal carotenoid conditioning orange pigmentation in the orange-flesh genotypes, the former two carotenoids also contribute significantly to the total content and thus to the orange phenotype.

The three commercial cvs. Atlantic, Spunta, and YG had carotenoid profiles typical of white- and yellow-flesh potato cultivars, except YG had a minor amount of zeaxanthin, as mentioned previously. Recognizing that the appearance of white vs. yellow flesh is hard to state subjectively, the paradox in this study is MSU genotype J132-1Y, a white-flesh line that would have been expected to have at least light yellow flesh, based on total carotenoid contents. 

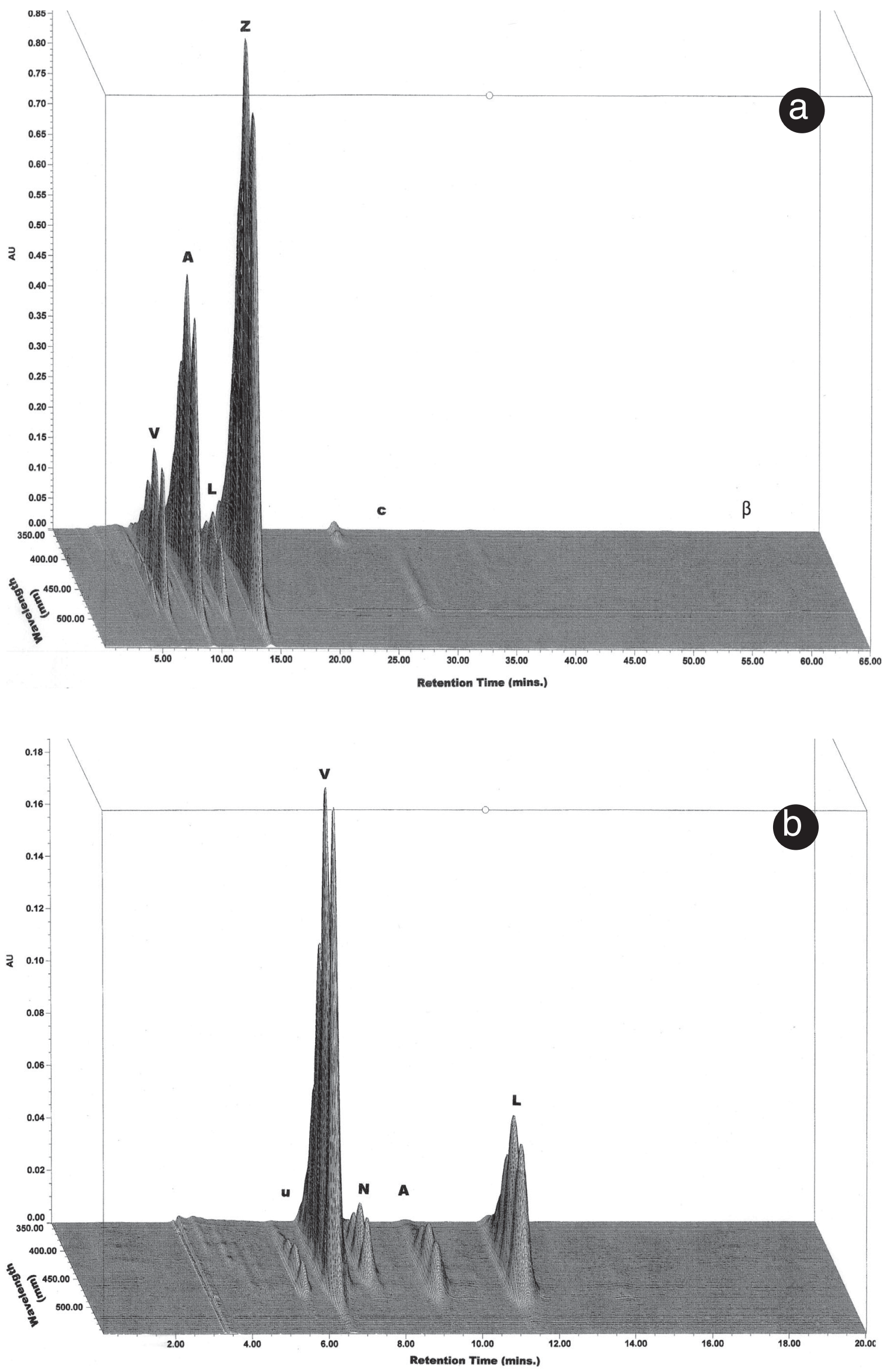

Fig.1. Chromatograms of carotenoids in four flesh pigment types of potato: (a) OR-4 (orange); (b) JO33-10Y (yellow); (c) I201-2PY (yellow-purple); (d) G274-3 (white). $\mathrm{V}=$ violaxanthin; $\mathrm{N}=$ neoaxanthin; $\mathrm{A}=$ antheraxanthin; $\mathrm{L}=$ lutein; $\mathrm{Z}=$ zeaxanthin; $\mathrm{C}=\beta$-cryptoaxanthin; $\beta=$ beta-carotene; $\mathrm{U}=$ unknown. $(\mathrm{See}$ next page for Fig. $1 \mathrm{c}$ and d.)

HortScience, Vol. 38(6), October 2003 

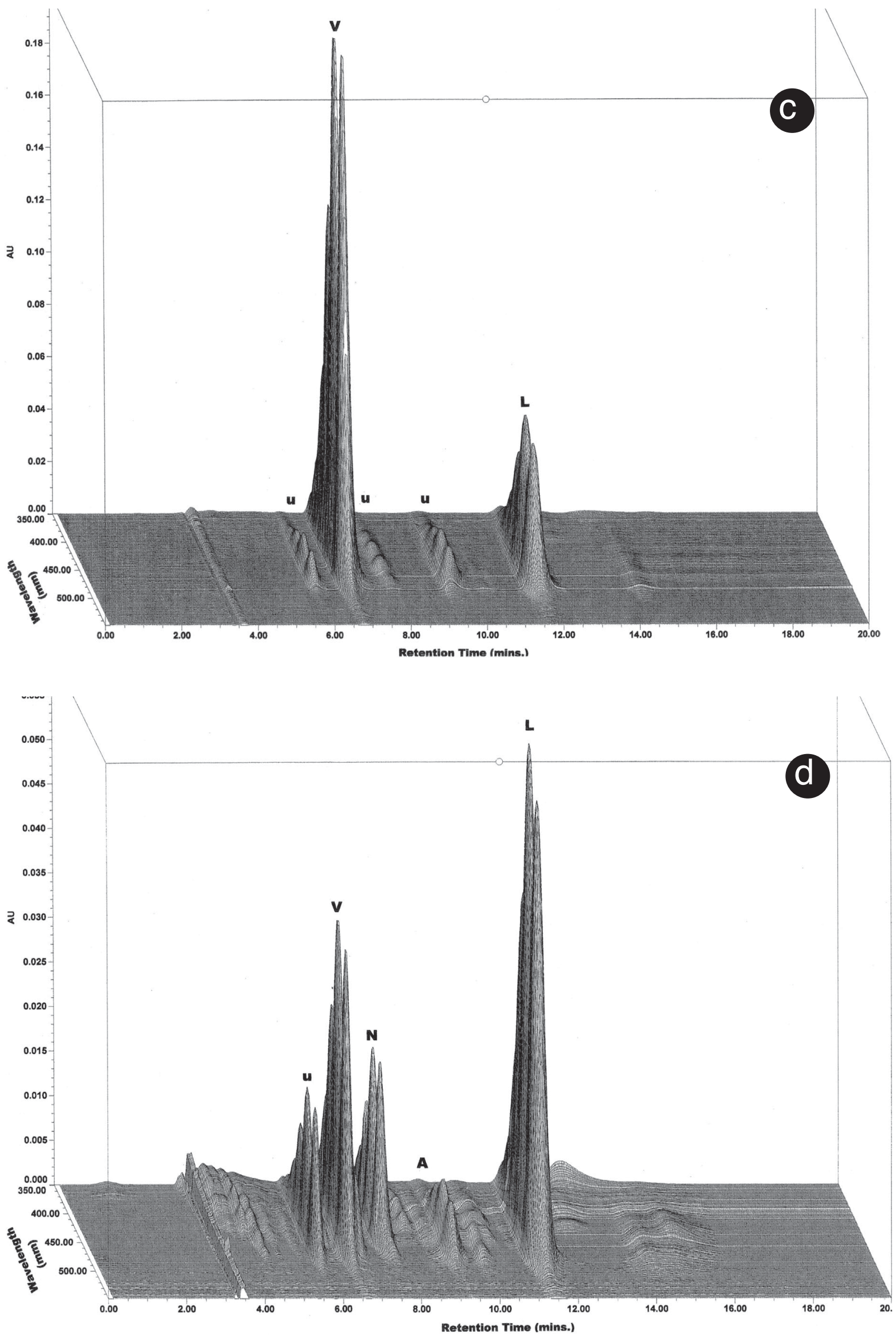

Fig.1. Chromatograms of carotenoids in four flesh pigment types of potato: (a) OR-4 (orange); (b) JO33-10Y (yellow); (c) I201-2PY (yellow-purple); (d) G274-3 (white). $\mathrm{V}=$ violaxanthin; $\mathrm{N}=$ neoaxanthin; $\mathrm{A}=$ antheraxanthin; $\mathrm{L}=$ lutein; $\mathrm{Z}=$ zeaxanthin; $\mathrm{C}=\beta$-cryptoaxanthin; $\beta=$ beta-carotene; $\mathrm{U}=$ unknown. $($ See previous page for Fig. $1 \mathrm{a}$ and $\mathrm{b}$.) 
This line had the highest lutein content, 119 $\mu \mathrm{g} \cdot 100 \mathrm{~g}^{-1} \mathrm{FW}$, relatively high violaxanthin, and the second highest total carotenoid content. $\mathrm{J} 132-1$ is an $\mathrm{F}_{1}$ derived from the cross Lenape $x$ Zarevo. Interestingly, the cv. Atlantic studied here also has in common 'Lenape' as a parent, but while 'Atlantic' and J132-1 have the same two major carotenoids, violaxanthin and lutein, they are present in the former cultivar in much lower levels. HPLC analysis of the parents of 'Atlantic' and J132-1 may reveal the origin of these profile differences.

Except for MSU-J132-1Y, all white-flesh lines in the breeding program studied had a total carotenoid content ranging from 37.6 to $86.9 \mu \mathrm{g} \cdot 100 \mathrm{~g}^{-1} \mathrm{FW}$ for H031-5 and J168$2 \mathrm{Y}$, respectively, while the yellow-flesh lines ranged higher, from 107.5 to $260 \mu \mathrm{g} \cdot 100 \mathrm{~g}^{-1}$ FW for J033-6Y and E048- 2Y, respectively (Fig. 1). This confirms the observations by $\mathrm{Lu}$ et al. (2001), where a diploid white-flesh potato clone studied had total carotenoids of 100 $\mu \mathrm{g} \cdot 100 \mathrm{~g}^{-1} \mathrm{FW}$, and the range for the 10 diploid yellow-flesh clones was from 136 to a much higher level of $1435 \mu \mathrm{g} \cdot 100 \mathrm{~g}^{-1} \mathrm{FW}$.

In summary, lutein and zeaxanthin were the carotenoids of particular interest in our study in view of their potential health benefit protection for AMD. The new advanced technology to measure levels of these two carotenoids in the retina in vivo should create information on the levels needed for eye health (Mares-Perlman et al., 2002). Lutein varied significantly among the 15 lines, while zeaxanthin was observed only in one line and at a low level. Potato can be enhanced for carotenoids, and lutein is known to be correlated with yellow flesh such that indirect selection for its increase, as opposed to tedious and expensive HPLC analyses, is possible (Lu et al., 2001). Zeaxanthin, on the other hand, would need to be increased through use of diploid genetic stocks carrying the $\mathrm{Or}$ gene (Brown et al., 1993). The introgression of this diploid germplasm to the cultivated tetraploid level could easily be achieved if $2 n$ gametes occur. Not to be overlooked, from the nutrition health viewpoint, is $\beta$-carotene. It has been reported only twice (Brunstetter and Wiseman 1947; Iwanzik et al., 1983) prior to this study in potato and only in small amounts. Whether lutein, zeaxanthin, and $\beta$ carotene profiles can be enhanced in potato remains to be determined. The baseline data we have established provides a starting point for such nutrient enhancement in potato.

\section{Literature Cited}

Bonierbale, M.W., R.L. Plaisted, and S.D. Tanksley. 1988. RFLP maps based on a common set of clones reveal modes of chromosomal evolution in potato and tomato. Genetics 120:1095-1103.

Britton, G., S. Liaaen-Jensen, and H. Pfander. 1999. Carotenoids. Vol.1A: Isolation and analysis. Birkhauser Verlag, Boston.

Brown, C.R., C.G. Edwards, C.-P. Yang, and B.B. Dean. 1993. Orange flesh trait in potato: Inheritance and carotenoid content. J. Amer. Soc. Hort. Sci. 118:145-150

Brunstetter, B.C. and H.G. Wiseman. 1947. Carotenoid pigments in tubers of the Katahdin variety of Irish potato. Plant physiol. 22:421-437.

Curran-Celentano, J., B.R. Hammond Jr., T.A. Ciulla, D.A. Cooper, L.M. Pratt, and R.B. Danis. 2001.
Relation between dietary intake, serum concentrations, and retinal concentrations of lutein and zeaxanthin in adults in a Midwest population. Amer. J. Clinical Nutr. 6:796-802.

Fruwirth, C. 1912.ZurZuchtung der Katoffel. Dtsch Landw. Presse 39:551-552, 565-567.

Haynes, K.G. 2000. Inheritance of yellow-flesh intensity in diploid potatoes. J. Amer. Soc. Hort. Sci. 125:63-65.

Iwanzik, W., M. Tevini, R. Stute, and H. Hilbert. 1983. Carotiniodgehalt und-zusammensetzung verschiedener deutcher kartoffelsorten und deren bedeutung fur die fleischfarbe der knolle. Potato Res. 26:149-62.

Giovannucci, E. 1999. Tomatoes, tomato-based products, lycopene, and cancer: Review of the epidemiologic literature. J. Natl. Cancer Inst. 91:317-331

Lessin, W.J., G.L.Catigani, and S.J. Schwartz. 1997. Quantification of cis-trans isomers of provitamin A carotenoids in fresh and processed fruits and vegetables. J. Agr. Food Chem. 45:3728-32.

Lu, W., K. Haynes, E. Wiley, and B. Clevidence. 2001. Carotenoid content and color in diploid potatoes. J. Amer. Soc. Hort. Sci. 126:722-726.

Mares-Perlman, J.A., A.E. Millen, T.L. Ficek, and S.E. Hankinson. 2002. The body of evidence to support a role for lutein and zeaxanthin in delaying chronic disease. J. Nutr. 132: $518 \mathrm{~s}-524 \mathrm{~s}$.

Mayne, S.T. 1996. Beta-carotene, carotenoids, and disease prevention in humans. FASEB J. 10: 690-701.

Pendlington, S., M.S. Dupont, and F.J. Trussell. 1965. The carotenoid pigments of Solanum tuberosum. Proc. Biochem. Soc. p. 65-66.

Taungbodhitham, A.K., G.P. Jones, M.L. Wahlqrist, and D.R. Briggs. 1998. Evaluation of extraction methods for the analyses of carotenoids in fruits and vegetables. Food Chem. 63:4577-4584. 